\title{
Del Modernismo a la Vanguardia: la Estética del Haikú .
}

En la literatura modernista de lengua española, se puede hablar de varios tipos de "orientalismo". Hacia finales del siglo $\mathrm{xIX}$, surgió uno que puede clasificarse de superficial o epidérmico. Se trata del mero empleo de objetos, motivos y temas orientales para crear un ambiente exótico en el poema. Tal exotismo gozó de popularidad, sobre todo en los comienzos del modernismo. Era un hermoso ropaje que tenía el encanto de lo desconocido y satisfacía un gusto especial para todo lo lejano.

Se puede hablar también de otro orientalismo, más hondo y pertinente a este estudio, aunque todavía no sea quizái el más significativo. Se trata del interés por las disciplinas filosóficas del Oriente, tan importantes para los escritores, "decadentes" o simbolistas. Ellos se aficicnaban al budismo, al taoísmo, al zen y a la teosofía en general, porque estos sistemas les ofrecían un nuevo modo de acercarse a la realidad y expresar una experiencia personal. Estas preocupaciones metafísicas son especialmente sugestivas cuando las consideramos a la luz de los ideales artísticos de la época. Los poetas querían evocar en su poesía una realidad "más allä" de la experiencia ordinaria, y mediante un lenguaje de máxima sugestividad, llevar al lector al conocimiento directo de ella. Además, en su poesía hablaban de buscar la esencia de esa realidad, de tal modo que el "alma de las cosas" llegó a ser tema en la poesía de algunos; de mado especial, en escritores como Rubén Darío, Amado Nervo, Enrique González Martínez y otros. Es difícil precisar hasta qué punto fueron influidos por esas aficiones orientales y místicas, pero no se puede negar las coincidencias entre sus preocupaciones estéticas y ciertos principios orientales: Ia clara conciencia de una realidad del "más allä"; el deseo de conocer esa realidad por medios intuitivos; y la necesidad de sumergirse en la realidad para sentir y expresar el "alma de las cosas". En todo caso, habría que tomar en cuenta este orientalismo de aspecto metafísico, como fase de cierta importancia en el desarrollo de la estética modernista. 
Sin embargo, a mi juicio, el orientalismo más importante en la evolución de la literatura modernista, es la adaptación del haikú a la poesía de lengua española. Importante, porque el haikú representa la esencia de la estética oriental, derivada a su vez de las ya mencionadas direcciones del pensamiento filosófico; e importante porque el haikú, que floreció en la poesía española hacia la década de los '20, fue otra manifestación del espíritu de vanguardia. Los devotos de los "ismos" de aquel entonces, daban primacía a la metáfora poética, cuya función era la creación de nuevas realidades intuidas por la imaginación. El hecho es que el haikú se ofreció como molde adecuado para la imaginería vanguardista. Las coincidencias estéticas entre esa antigua poesía oriental, y la que emergía en tiempos modernos en el Occidente, son fundamentales. Es este orientalismo de raíz estética el que ha de ocuparnos aquí.

Si vamos a estudiar el paralelismo estético entre la poesía de vanguardia y el haikú, es necesario establecer primero algunas premisas del pensamiento oriental y su manifestación en el haikú. Entre las grandes religiones ya nombradas, pueden distinguirse varias actitudes básicas. ${ }^{1}$ Primero, como hemos dicho, la conciencia de una realidad del "más allä". Allí se reconcilian todos los aspectos diversos de la realidad. La unidad de ésta consiste en la diversidad de sus apariencias, y no hay jamás contradicción alguna. Por lo tanto su carácter es dinámico, nunca fijo. Todo esto quiere decir que la verdad de una cosa es la suma de sus apariencias; y que ninguna representación de ella es menos verdadera que otra. Finalmente, es una realidad donde se identifican y se compenetran todas las cosas. Por eso, cuando descubrimos relaciones escondidas y misteriosas entre las cosas alcanzamos una verdad más allá de la percepción normal. Penetramos en la Gran Realidad.

Otro aspecto importante del pensamiento oriental se refiere a la relación que existe entre el individuo y su realidad ambiente. Para transcender la experiencia ordinaria, uno ha de "salir de sí", dejando atrás la conciencia de sí mismo para identificarse completamente con lo contemplado. El hombre es uno con la naturaleza, aunque se sienta aislado y solo. En el instante en que se olvida de sí y percibe la unidad entre las cosas, alcanza su dimensión completa. El individuo, el sujeto, se une al objeto, haciéndose uno con el Gran Todo.

1 La información sobre la estética y las religiones orientales ha sido tomada principalmente de los libros siguientes: Alan W. Watts, The W ay of Zen (New York: Random House, 1957); Daisetz T. Suzuki, Zen and Japanese Culture (Princeton, N. J.: Princeton University Press, 1959); Hugo Munsterberg, Zen and Oriental Art (Tokyo: Charles E. Tuttle Co., 1971); y Chang Chung-yuan, Creativity and Taoism (New York: Harper and Row, 1963). 
Consideremos ahora las implicaciones estéticas de estos principios, tal como se manifiestan en el haikú. En la definición de R. H. Blyth, el haikú es "la expresión de una breve iluminación, en la cual vemos la vida de las cosas."2 Agrega el profesor Zuzuki: "Si breve o no, Bashó nos da en sus diecisiete sílabas una importante intuición respecto a la Realidad." 3 Para nosotros, lo más significativo es que ambos críticos definen el haikú en términos de una experiencia. Y en efecto, lo es. Insisto: el haikú es la expresión poética de una intuición, en la cual el poeta ha descubierto, en un instante, la Gran Realidad. Es la recreación verbal del satori, o sea, el momento de la iluminación.

Además, las características del haikú corresponden a los principios metafísicos ya vistos. ${ }^{4}$ Formalmente, el haikú es, ante todo, breve; y esta brevedad se debe en gran parte a la "ausencia." del poeta. Según la tradición del haikú, el poeta no debe expresar sus propios sentimientos sobre la realidad representada en el poema. Ha de ser el agente pasivo que señala solamente los mínimos elementos necesarios para recrear su visión. Como consecuencia de esa actitud, se nota la falta de palabras abstractas y elementos discursivos. De eso procede la brevedad de la expresión. Hay que subrayar la correspondencia entre este concepto del prema y el fenómeno del satori. Al ausentarse de su obra, el poeta se limita e evocar la realidad que le impresionó, olvidándose de sí mismo. Tiene que "salir de sí", como está prescrito, para lograr satori. A su vez, la propia brevedad del haikú se asemeja al instante de la iluminación.

También en los terras del haikú se refleja la actitud oriental ante la realidad. Así como el taoísmo y el zen piden la "identificación y compenetración" del individuo con la realidad que le rodea, el haikú se hace de realidades inmediatas a todos. De ahí, por ejemplo, la frecuente presencia de la naturaleza en el haikú japonés. Aparte de la reverencia del mundo natural en la cultura japonesa, dicho mundo es el punto de partida para tantos pcemas por su misma proximidad. En el haikú se atestigua el despertar del poeta a un cercano fenómeno natural. Es más: muchas veces la naturaleza se emplea en el haikú para facilitar la identificación del lector con la experiencia poetizada. Un pájaro o una planta sugiere una estación del año, que evocará cierto sentimiento universal. Tal "palabra-estación" ayuda a establecer el tono del poema, acercando

\footnotetext{
2 R. H. Blyth, citado por Daisetz T. Suzuki en Zen and Japanese Culture, p. 228.

3 Suzuki, ibid.

- Además de los libros indicados, han sido consultados para el haikú los siguientes: Donald Keene, Japanese' Literature' (New York: Grove Press, 1955) y An Introduction to Haikin, por Harold Henderson (New York: Doubleday, 1958).
} 
al lector a la emoción del poeta. Ocurre igual con el empleo de otros elementos de la existencia diaria. Un objeto familiar tendrá algún sentido universalmente conocido, mientras forma parte de una experiencia particular para el poeta y cada lector. Por el carácter asequible de sus temas, pues, el haikú ofrece un instante de mayor comprensión del mundo.

Por otro lado, es notable que en el haikú aparezca no sólo lo más bello de la naturaleza o de la vida diaria, sino también cosas pequeñas, ordinarias y hasta desagradables. Este uso de elementos nimios o displicentes en la poesía corresponde a la creencia de que tada realidad, por humilde que sea, puede provocar satori. Asimismo, en el haikú puede ser poetizado cualquier fenómeno.

Finalmente, un estudio de las imágenes en el haikú revela la flexibilidad de la visión del poeta. A veces se presenta una visión insólita de algo familiar; otras veces, una relación sorprendente entre dos cosas dispares. En todo caso, sentimos el dinamismo de la realidad, y nos damos cuenta de las infinitas posibilidades que nos of rece. En este sentido, también el haikú hace eco de las religiones orientales, en las culales se insiste en que no haya concepto fijo de la realidad. Recordemos aquí la cbservación de Octavio Paz:

El ponsamiento oriental no ha padecido este horror a lo "otro", a lo que es y no es al mismo tiempo. El mundo occidental es el del "esto o aquello"; el oriental, el del "esto y aquello" y' aun el de "esto es aquello". 5

Es una actitud que da origen a una mayor flexibilidad en la interpretación de la experiencia, tanto como en la imagen poética.

Definido el haikú como manifestación artística de ciertos principios estéticos del Oriente, pasamos a ver ahora lo que era el haikú para los poetas de habla española. Evidentemente, la forma estricta japonesa - de diecisiete sílabas en disposición de cinco/ siete/ cinco- no les interesaba demasiado. Además, en la versión española se solía observar la rima, y a veces se daba título al poema, elementos formales que jamás tuvo el haikú japonés. Lo que atraía a los poetas de lengua española fue la brevedad del haikú y la manera en que se presentaban las cosas. Esta actitud se aproximaba a una estética muy cara a sus propias inclinaciones.

5 Octavio Paz, El atco y la lira (México: Fondo de Cultura Económica, 1956), p. 102. 
Para comprobar si en efecto comprendieron los poetas lo que significaba el haikú y sus intenciones, consideremos primero el concepto del haikú que tenía el mexicano José Juan Tablada, ya que él fue quien lo introdujo a esta lengua. A modo de prólogo al Itinerario contemplativo de Francisco Monterde, Tablada escribió unos versos sobre el haikú. El libro, publicado en 1923, es una colección de graciosos poemitas, instantáneas de un viaje a Veracruz. Del prólogo, titulado "Elogio del buen haijín", sabemos que los poemas de Monterde fueron concebidos como haikús. Efectivamente, lo eran; y a pesar de ciertos estudios que tienden hacia una clasificación cada vez más rigurosa del haikú, siguen siéndolo. Copio a continuación algunos versos del prólogo de Tablada que tienen interés particular para nuestro propósito:

Fuera de Asís si no fuera de Budha;

La esencia del Logos, el baijín lo sabe,

Duerme en la planta y en la piedra es muda,

Perfuma en las flores y canta en el ave.

......

Canta en la gloria del instante

La flor, la piedra, el animal...

Máxima in minima es humilde

Lema en su rústico blasón;

......

Para el haijín no hay trivial cosa.

Todo un drama cabe en un grito;

.......

Va electrizando su emoción

Con la chispa de la sorpresa,

.......

$\mathrm{Y}$ discierne del animal

$Y$ la flor las almas hermanas,

Con esa armonía cabal

Del paraíso terrenal

$\mathrm{Y}$ las bateas michoacanas... ${ }^{\circ}$

No creo que haga falta señalar cuáles versos corresponden tácitamente a los principios orientales que hemos puntualizado hasta ahora. Por lo

6 José Juan Tablada, en el prólogo al Itinerario contemplativo de Francisco Monterde (México: Editorial Cultura, 1923), pp. 15-24. 
tanto, parece bien evidente que Tablada tenía amplio e intimo conocimiento del arte del haikú. Para prueba adicional, tencmos los volúmenes suyos dedicados a este tipo de poesía: Un Día... (1919) y El Jarro de flores (1922).

Hay quienes opinan que el cultivo del haikú en el occidente y específicamente en lengua española, fue únicamente el resultado de una moda. En el caso de México, por influencia francesa. John Page, en su excelente estudio de Tablada como intraductor del haikú al español, apunta una serie de hechos que demuestran la influencia de la antología de Michel Revón en los haikús del mexicano. Concluye Page que el impulso definitivo a escribir haikú, le vino de los franceses, y no de los japoneses. A mi juicio, sin embargo, lo más significativo es lo que afirma luego: "La admiración [de Tablada] ante la concisión impresionista es igual a la de Revón."7 Page da una nómina de las características del arte del haikú, como lo practicó Tablada. Entre otras modalidades señaladas: la evocación de un sentimiento trascendental, representado por una manifestación natural; la inspiración en las pequeñas cosas de la naturaleza, hasta en sus aspectos más humildes; y el sentido de "el todo es uno" del budismo Zen."' No cabe duda de que el poeta mexicano recogió no sólo una breve forma poética, entonces de moda, sino también una estética implícita en el haikú. Además, como Tablada fue el intérprete del haikú para los jóvenes poetas de su círculo, podemos suponer que ellos también entendieron la esencia del haikú. Y que ellos lo cultivaron porque, consciente $o$ inconscientemente, encontraton en esa esencia algo suyo:

Otro testimonio de lo que se entendía por haikú on el ambiente mexicano se halla en el artículo de José María González de Mendoza titulado "El 'haikai' japonés y los poemas sintéticos mexicanos". 9 Después de referirse a la "escuela de 'haijines' mexicanos" - a poetas como Monterde, José Rubén Romero, Carlos Gutiérrez Cruz, José D. Frías y Rafael Lozano- el mismo crítico habla de varios estudios franceses e ingleses sobre la poesía japonesa. Cita primero a Revón, quien destacó el aspecto inacabado o "abierto" de esta poesía, lo cual invita a la participación del lector. Luego cita una observación del inglés 'W. G. Aston: la de que la característica predominante en la poesía japonesa es la expresión de alguna emoción íntima. El japonés Kenko había dicho, "comprender el

7 John G. Page, José Juan Tablada, introductor del baikai en Hispanoamérica (México: UNAM, 1963), p. 50.

3 Ibid., p. 70 .

9 José Matía González de Mendoza, "El 'haikai' japonés y los "poemas sintéticos' mexicanos", La antorcha, 14 de febrero de 1925, pp. 17-18. 
¡Ah! de las cosas". ${ }^{10}$ El Abate de Mendoza se refiere también a la descripción de Paul Guchoud, quien desecha la importancia de la forma en el haikú, para quedarse con su esencia, "sensación pura, eliminando lo abstracto". ${ }^{11}$ Este resumen de ideas ajenas sobre el haikú es importante, primero porque en cada comentario el énfasis está en el haikú como experiencia vital; y segundo, porque todas esas definiciones confirman el entendimiento del haikú que había en el ambiente literario mexicano.

González de Mendoza termina por reconocer una infinita variedad de haikú, concluyendo que la que predominaba entre los mexicanos presen. taba una imagen ingeniosa de la realidad. Para ilustrar su tesis, cita el siguiente haikú del japonés Yamasaki Sokán:

Si se le aplicara

un mango a la luna

¡qué bello abanico! ${ }^{12}$

Se representa aquí una intuición repentina, una chispa que saltó entre la realidad de la luna y la imaginación del poeta, que luego se concretó en una imagen sorprendente.

El Abate de Mendoza no llegó a decir, en 1925, si el haikú era moda pasajera o forma incorporada definitivamente a la lírica mexicana. Lo que sí señaló fue la importancia estética del pequeño poema:

El haikai puede ser una excelente disciplina estética de pensamiento y de estilo; para la obra futura quedarán las cualidades adcuiridas: precisión, concisión, elegancia, simplicidad, sinceridad, finura, originalidad y sobria armonía. ${ }^{13}$

Ahora, con la perspectiva del tiempo, podemos afirmar decididamente que el haikú se incorporó a la poesía mexicana. Lo cultivaron ocasionalmente otros poetas, como Jaime Torres Bodet, Manuel Maples Arce, José Gorostiza, Carlos Pellicer, Xavier Villaurrutia; y años después recibió nuevo ímpetu con las traducciones de Octavio Paz. ${ }^{14}$ Lo que es más, tanto en México como en otros países, el haikú sigue ejerciendo un atractivo especial para ciertos escritores. Es significativo, creo, que Monterde, siendo uno de los primeros haijines mexicanos, publicó en

10 Citado en la primera parte del artículo, 7 de febrero de 1925, p. 12.

11 Paul Couchoud, citado por González de Mendoza, ibid.

12 Citado por González de Mendoza, ibid., p. 26.

13 González de Mendoza, en la segunda parte del artículo, p. 18.

14 Octavio Paz y Eikichi Hayashiya, trads., Sendas de Oku de Matsuo Basho (México, 1957). 
1962 la que son tal vez sus mejores haikús. ${ }^{15}$ Comprueba, a mi modo de ver, la actualidad del espíritu del haikú.

Pasemas ahora a España, donde no hubo "escuela" de haijines, pero sí había poctas que cultivaron el breve poema sintético con buenos resultados. La mayoría de los haikús españoles aparecieron durante los años veinte, es decir, en época posterior a los libros citados de Tablada. Sin embargo, es probable que el mayor impulso hacia el haikú no haya venido de México sino de Francia y, en menor grado, de Inglaterra. Aunque es casi imposible resolver el asunto de precedentes en este caso (y tampoco es la cuestión central), quisiera recordar aquí un comentario de Enrique Díez Canedo, que pertenece a un artículo sobre Tablada publicado en España:

Se engañaría el que creyera que Tablada se las da de precursor del "haikai" europeo: no hace más que establecer su prioridad en cuanto a la lengua castellana, ya que el florecimiento español, y parte del americano, en cuanto al "haikai" procede de la fuente francesa que marca a su vez precursores: el libro de Couchoud, Sages et poètes d'Asie, las versiones inglesas de B. H. Chamberlain. No sería difícil encontrar en Lafcadio Hearn y en poetas angloamericanos de hoy otros precedentes. ${ }^{16}$

Lo que quizás debiera haber mencionado Díez Canedo, tanto por su fecha temprana como por su calidad, fue el estudio anterior de Enrique Gómez Carrillo, primero publicado en El nuevo mercurio de Barcelona en 1907, y recogido en su libro El alma japonesa. ${ }^{17}$ En el artículo original, titulado "El sentimiento poético japonés", Gómez Carrillo demuestra su conocimiento de la estética oriental, al establecer las características principales de la poesía japonesa. Explica, por ejemplo, la "palabra almohada' y la 'palabra eje', que son tan importantes para la sintesis y profundidad de los poemas breves. ${ }^{18}$ Es digno de notarse que la exposición

\footnotetext{
15 Francisco Monterde, Nétsuke (México: Finisterre, 1962)

16 Enrique Díez Canedo, "Letras de América: Tablada", España, 17 de febrero de 1923 , p. 11.

17 Enrique Gómez Carrillo, "El sentimiento poético japonés", El nuevo mercurio, abril, 1907 , pp. 444-459.

$18 \mathrm{La}$ 'palabra almohada' sirve par agregar a la realidad poctizada un matiz particular. Un ejemplo citado por González de Mendoza es "volátil doméstico", para decir "gallo". No llega a ser un clisé, sino, como lo define Chamberlain, una expresión prefija a otra, meramente por eufonia, en la que descansa la principal "lo mismo que la cabeza sobre una almohada".

La 'palabra eje', que suele tener un doble sentido, sirve para unir las dos partes de un conjunto. Gómez Carrillo cita la siguiente estrofa castellana para ilustrar la función de la 'palabra eje':
} 
que hace de estos términos anticipa en dieciocho años el artículo citado de González de Mendoza, quien tradujo los mismos términos 'palabra almohada' y 'palabra pivote', y describió su función respectiva. ${ }^{10}$ Gómez Carrillo acertadamente subraya la importancia de la síntesis, diciendo que en la literatura japonesa, "un poema es un suspiro a una exclamación, una alegoría o una imagen","20 que no se desarrolla con amplitud. El poeta japonés "desconoce lo que es labor de artífice, esfuetzo de artista, cultura de orfebre. Lo que le interesa es sugerir o evocar mucho con pocas palabras. . " ${ }^{21}$ Conviene advertir que Tablada, por su parte, calificó su culto al haikú como "una reacción contra la zarrapastrosa retórica." 22 Para Tablada y los demás aficionados, el haikú era el ejemplo por excelencia de la sugestividad y la síntesis.

También Gómez Carrillo compara el ideal poético representado por el haikú con el simbolismo occidental. Habiendo observado que la misión del poeta japonés es "hacer entrever un pensamiento disimulado entre pocas palabras", pregunta: "¿No descubrís en estas líneas algo de las teotías mallarmeanas? La doctrina de la sugestión partía de un principio análogo". ${ }^{23}$

No obstante, el artículo se destaca ante todo por el hecho de que Gómez Carrillo, ya pơr 1907, explicaba el haikú en España, y en profundidad. Además, se apoyaba en los destacados críticos ingleses, W. G. Aston (Japanese Litenature) y Basil Hall Chamberlain (Classical Poetry of the Japanese), junto con varios poetas y críticos japoneses, contemporáneos y antiguos. El artículo demuestra, pues, que había en España un conocimiento auténtico y precoz de la estética japonesa a través de su poesía; y con ello, lo que era haikú.

Más tarde, cuando se escribieron haikú en España, aparecieron otros comentarios sobre la naturaleza del pequeño poema, y en algunos se relaciona el haikú con la estética occidental moderna. José Moreno Villa, en su reseña del libro de Paul Couchoud (Sages et poètes d'Asie) califica la sección titulado "Epigramas líricos del Japón" como "poesía discontinua,

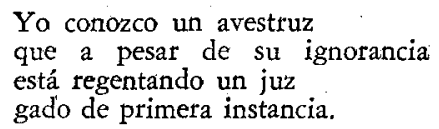

La palabra 'juzgado', claro está, es el 'eje' que une la primera a la segunda parte de la estrofa.

19 González de Mendoza, La antorcha, 7 de febrero de 1925, p. 11.

20 Gómez Cartillo, ibid., p. 453.

21 Ibid., p. 450.

22 José Juan Tablada, "Hokku", prólogo a El jarro de flores, recopilado en Obras, I (México: UNAM, 1971), p. 421.

${ }_{23}$ Gómez Carrillo, ibid., p. 451. 
nada oratoria, ni explicativa, tal como lo soñaba Mallarmé". ${ }^{24}$ Después de transcribir ocho de los haikús traducidos por Couchoud, Moreno Villa observó que esta poesía había venido influyendo en Europa desde el siglo anterior y que en Francia, durante la primera guerra mundial, se cultivaba mucho. Explicando la popularidad del haikú en esa época, dijo: "Realmente, para los momentos de emoción y peligro, nada se presta como el apunte, el haikú". ${ }^{25}$ Su observación es otro testimonio del concepto que se tenía del haikú en España: no como una curiosidad exótica, sino como una forma expresiva adecuada al mundo actual.

Adolfo Salazar hizo algunas observaciones importantes sobre el haikú, a modo de introducción a unos poemas suyos en 1920. Dijo que la identidad métrica, scslayada desde el principio por los franceses, no era lo esencial, sino lo siguiente:

...el núcleo poético encerrado en el Hai-Kai, su concepto de una forma leve y redonda. . menuda a tenir dans la main y ágil como un éter, el motivo principal para la sugestión. ${ }^{26}$

Describió el haikú como "un puntilismo de sensaciones que construya la imagen en el fondo de la intuición".27 Salazar indicó algunas características del haikú japonés, destacando a la vez las variaciones en la versión europea. Luego, como en defensa del haikú occidental, afirmó:

No se trata de reproducir una forma exótica característica, sino que, penetrado su principio, pueda servir para sujetar alguno de los vivos destellos que se escapan por los intersticios de la poesía occidental. ${ }^{28}$

La lista de españoles que escribieron versos a estilo haikú incluye a poetas como Guillermo de Torre, Adriano del Valle, Francisco Vighi, Antonio Espina Garcia, Juan José Domenchina y Gerardo Diego. Lo más sugestivo para nosotros es que, como ocurrió en México, algunos de estos poetas representan la vanguardia de su país. Suponiendo que sabian, por varias vías, lo que realmente era el haikú; y que se inclinaban al mismo tiempo, hacia los "ismos" contemporáneos, habría que pensar

24 José Moreno Villa, La pluma, junio de 1920, p. 46.

25 Ibid., p. 47.

26 Adolfo Salazar, "Proposiciones sobre el Hai-kai", La pluma, noviembre de 1920, p. 269.

27 Ibid.

28 Ibid., pp. 269-270. 
en la simpatía entre el haikú y los ideales estéticos de la vanguardia. Tablada ya había sugerido esta afinidad estética en su prólogo a $E l$ jarro de flores:

El haikai, de floral desnudez, no necesita búcaros, y es por esencia el justo vehículo del pensamiento moderno, tema lírico puro, adámico como la sorpresa y sabio como la ironía. ${ }^{29}$

En virtud de la estética del haikú, puede concluirse que su ideal es expresar on pocas palabras nuevas experiencias, mediante un conocimiento intuitivo de la realidad. Ese procedimiento creador supone la liberación del individuo de los límites del lenguaje y del proceso puramente intelectual. Hay que reconocer que esto es, al mismo tiempo, la base teórica de todos los "ismos". ¿Qué representan los movimientos de vanguardia, si no una reacción contra el desarrollo discursivo y el análisis sentimental en el poema? ¿No es suyo el propósito de crear nuevas realidades, sorprendiendo la potencia poética de la realidad inmediata, para liberarnos del tedio del lenguaje y de la lógica? El haikú japonés y la poesía de vanguardia nacieron de ambientes distintos y con tonos diferentes, pero la actitud ante la realidad y el concepto de poesía son esencialmente iguales. El anhelo de síntesis y condensación, de evocación y sugerencia, empezó con el simbolismo francés para encontrar su apogeo en la vanguardia. Una de sus formas: el haikú.

Barbara Dianne Cantella

University of Texas

29 José Juan Tablada, "Hokku", Obras, p. 421. 
